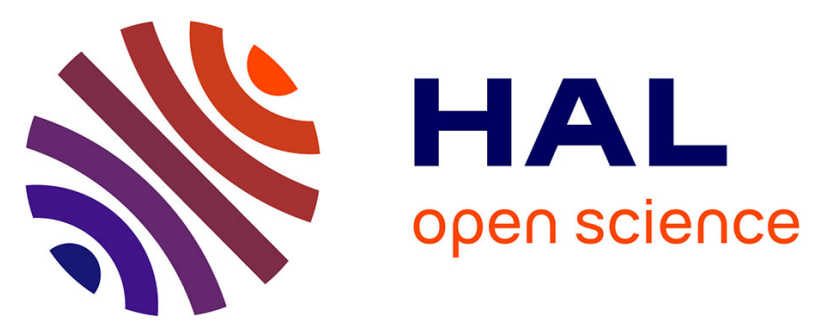

\title{
Improving the Control Performance of an Organic Rankine Cycle System for Waste Heat Recovery from a Heavy-Duty Diesel Engine using a Model-Based Approach
}

Johan Peralez, Paolino Tona, Olivier Lepreux, Antonio Sciarretta, Luce Voise, Pascal Dufour, Madiha Nadri

\section{To cite this version:}

Johan Peralez, Paolino Tona, Olivier Lepreux, Antonio Sciarretta, Luce Voise, et al.. Improving the Control Performance of an Organic Rankine Cycle System for Waste Heat Recovery from a HeavyDuty Diesel Engine using a Model-Based Approach. 2013 IEEE Conference on Decision and Control (CDC), Dec 2013, Florence, Italy. 7 p. hal-00875469

\section{HAL Id: hal-00875469 \\ https://hal-ifp.archives-ouvertes.fr/hal-00875469}

Submitted on 22 Oct 2013

HAL is a multi-disciplinary open access archive for the deposit and dissemination of scientific research documents, whether they are published or not. The documents may come from teaching and research institutions in France or abroad, or from public or private research centers.
L'archive ouverte pluridisciplinaire HAL, est destinée au dépôt et à la diffusion de documents scientifiques de niveau recherche, publiés ou non, émanant des établissements d'enseignement et de recherche français ou étrangers, des laboratoires publics ou privés. 


\title{
Improving the Control Performance of an Organic Rankine Cycle System for Waste Heat Recovery from a Heavy-Duty Diesel Engine using a Model-Based Approach
}

\author{
Johan Peralez, Paolino Tona, Olivier Lepreux, Antonio Sciarretta, Luc Voise, Pascal Dufour, Madiha Nadri
}

\begin{abstract}
In recent years, waste heat recovery (WHR) systems based on Rankine cycles have been the focus of intensive research for transport applications, as they seem to offer considerable potential for fuel consumption reduction. Because of the highly transient conditions they are subject to, control plays a fundamental role to enable viability and efficiency of those systems.

The system considered here is an Organic Rankine Cycle (ORC) for recovering waste heat from a heavyduty diesel engine. For this system, a hierarchical and modular control structure has been designed, implemented and validated experimentally on an engine testbed cell.

The paper focuses more particularly on improving the baseline control strategy using a model-based approach. The improvements come from an extensive system identification campaign allowing model-based tuning of PID controllers and, more particularly, from a dynamic feedforward term computed from a nonlinear reduced model of the high-pressure part of the system.
\end{abstract}

Experimental results illustrate the enhanced performance in terms of disturbance rejection.

\section{INTRODUCTION}

More than one third of the energy produced by internal combustion engines (ICE) is released into the environment in the form of exhaust gas waste heat. Among the possible waste heat recovery (WHR) solutions, the Rankine cycle has drawn the attention of many car and truck manufacturers in recent years as it holds an interesting potential for reducing vehicle fuel consumption.

WHR Rankine systems for automotive applications apply the same principle used worldwide in industry to generate power, by converting heat into work. A pump circulates a working fluid in a closed loop where an external heat source supplies heat, via a heat exchanger (or a series of heat exchangers). Vaporized fluid expands

J. Peralez, P. Tona, O. Lepreux and A. Sciarretta are with the Control, Signal and System Department at IFP Energies Nouvelles, France \{johan.peralez, paolino.tona, olivier.lepreux, antonio.sciarretta\}@ifpen.fr

Luc Voise is with D2T Powertrain Engineering luc.voise@d2t.fr

P. Dufour and M. Nadri are with the Université de Lyon, F-69622, Lyon, France - Université Lyon 1, Villeurbanne, France - CNRS, UMR 5007, LAGEP, France \{dufour, nadri\}@lagep.univ-lyon1.fr in a turbine or an expander to produce mechanical power. Vapor is then cooled by a condenser which transfers heat to an external cold sink.

Most Rankine systems are designed to produce electricity via a generator connected to the auxiliary network and/or an energy storage system, even though, in mobile applications, the expansion machine can also deliver mechanical power directly to the transmission. The main differences with stationary applications lie in the limited capacity of the cold sink and in the highly transient behaviour of the hot source, both depending on driving conditions.

In this context, an effective control system is essential to attain satisfactory performance over a broad range of operating conditions. This is especially true when there are few available actuators and sensors, as it often happens in the automotive industry. Despite that, literature on control design for Rankine-based WHR for mobile application is still very scarce, as can be observed, for instance, in the comprehensive overview on Rankine WHR from internal combustion engines presented in [1].

The system considered here is an Organic Rankine Cycle (ORC) for recovering waste heat from a heavy-duty diesel engine. For this system, a hierarchical and modular control structure has been designed, implemented and validated experimentally on an engine testbed cell.

The focus is on improving the baseline control strategy using a model-based approach. The improvements come from an extensive system identification campaign allowing model-based tuning of PID controllers and, more particularly, from a dynamic feedforward term computed from a nonlinear reduced model of the high-pressure part of the system. The latter approach has first been proposed in [2] for a steam Rankine cycle, a different system where the presence of an additional actuator increases the degrees of freedom and makes model inversion simpler.

In this paper, on the one hand, we start studying the properties of the model-based control structure and, on the other hand, through a set of experimental results, we show that it actually works, achieving excellent performance. 


\section{STATE OF THE ART}

Among the few publications of practical interest discussing automatic control issues of Rankine WHR systems for automotive applications, we can cite [3] and, more recently, [4], both on steam processes for spark-ignition engines. [5] provides a complete (manual) startup and shut-down procedure for an ethanol-based Rankine cycle system, for heavy-duty applications, underlining the difficulty of controlling the working fluid conditions at the evaporator outlet.

On the more general topic of Organic Rankine Cycles for waste heat recovery operating with variable heat sources (not necessarily for transport applications), [6], [7], [8] apply control strategies based on linear models (LQR, MPC), validated on one operating point. [9] covers dynamic modeling and control of an ORC system with R234fa as a working fluid over a broader operating range. However, hot source variations used for simulation are much slower than those observed at the exhaust of an automotive engine, especially in terms of mass flow rate.

A somewhat richer literature is available on dynamic modelling and control of vapor compression cycles, the "reverse" of Rankine cycles ( [10], [11], [12]).

In both contexts, there is considerable interest in the development of simplified (moving-boundary, MB) models to reproduce the two-phase behavior of heat exchangers without the complexity of the finite-volume approach ( [13], [14]).

\section{SYSTEM DESCRIPTION}

The system considered here is illustrated in Fig. 1. It is an Organic Rankine Cycle system for waste heat recovery from a heavy-duty Diesel engine using a turbine for the expansion of the working fluid. A description of the main system variables follows, using the nomenclature given in Tab. I.

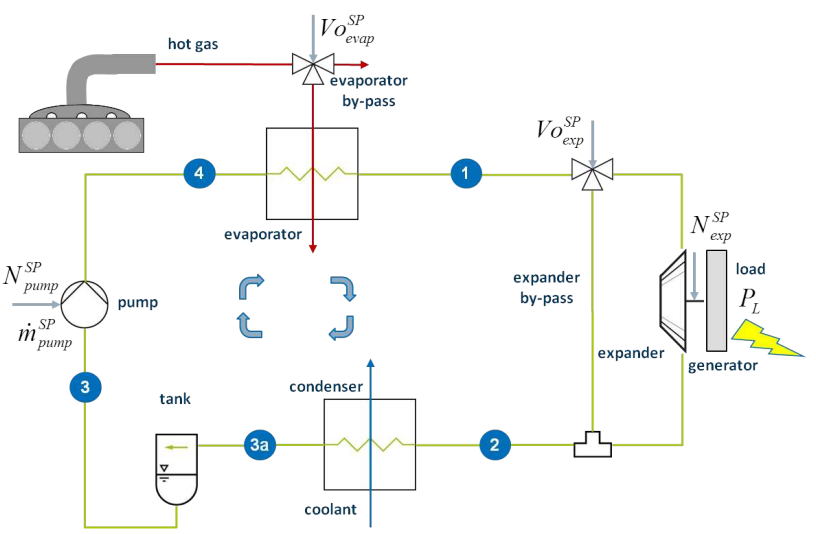

Fig. 1. The Organic Rankine Cycle system under investigation

\section{A. Inputs-outputs}

As shown in Fig. 2, measurements of the pressuretemperature pairs $(p, T)$ between each component are

\begin{tabular}{cc}
\hline Symbols & Volume $\left(\mathrm{m}^{3}\right)$ \\
$V$ & Area $\left(\mathrm{m}^{2}\right)$ \\
$S$ & Density $\left(\mathrm{kg} / \mathrm{m}^{3}\right)$ \\
$\rho$ & Heat transfer coefficient $\left(\mathrm{W} /\left(\mathrm{m}^{2} \mathrm{~K}\right)\right)$ \\
$\alpha$ & Heat capacity $(\mathrm{J} /(\mathrm{kg} \mathrm{K}))$ \\
$c$ & Specific enthalpy $(\mathrm{J} / \mathrm{kg})$ \\
$h$ & Mass $(\mathrm{kg})$ \\
$m$ & Mass flow rate $(\mathrm{kg} / \mathrm{s})$ \\
$\dot{m}$ & Pressure $(\mathrm{Pa})$ \\
$p$ & Temperature $(\mathrm{K})$ \\
$T$ & Normalized zone length $(-)$ \\
$L$ & Superheating $(\mathrm{K})$ \\
$S H$ & Rotation speed $(\mathrm{rpm})$ \\
$N$ & \\
Subscripts & evaporator \\
evap & expander \\
exp & exhaust gas \\
exh & working fluid \\
$f$ & wall \\
$w$ & zone i \\
$i$ & inlet \\
in & outlet \\
out & saturated vapor \\
$v$ & saturated liquid \\
$l$ & desired \\
$d$ & \\
Superscript & Set Point \\
SP & \\
& \\
&
\end{tabular}

TABLE I

Nomenclature

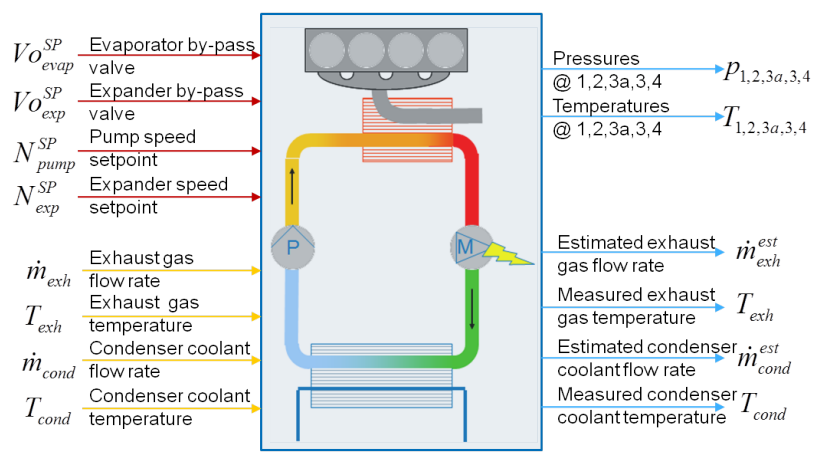

Fig. 2. ORC system inputs-outputs

available (corresponding to the corner points of the thermodynamic cycle, see Fig. 3). Exhaust gas and cooling fluid conditions (mass flow rate and temperature) can be considered as measured disturbances. The available measurements can be used to estimate key output variables such as superheating, subcooling or enthalpy, from fluid thermodynamic properties.

Four actuators are available, in principle:

- The evaporator by-pass setpoint $V o_{\text {evap }}^{S P}$, controlling the fraction of exhaust gas entering the evaporator.

- The expander by-pass setpoint $V o_{\text {exp }}^{S P}$, controlling the fraction of fluid entering the expander.

- The pump speed setpoint $N_{\text {pump }}^{S P}$ allowing to control the fluid mass flow $\dot{m}_{\text {evap in }}$ entering the evaporator.

- The turbine speed setpoint $N_{\text {exp }}^{S P}$. 


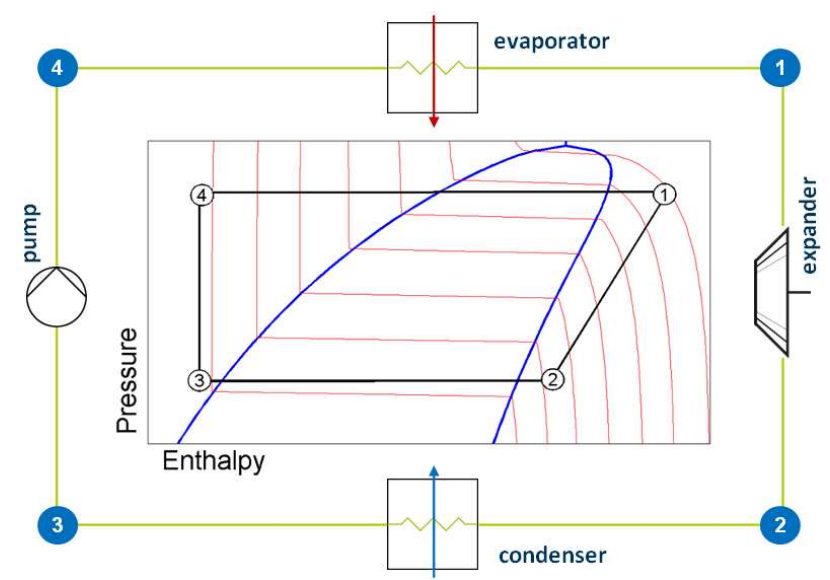

Fig. 3. Rankine cycle for "dry" fluid

\section{B. Control requirements}

The main objective of the supervision and control system is to maximize, in the presence of varying external conditions, the production of electric energy during vehicle usage (assuming that the load control system can always make use of it, or dissipate it, otherwise).

Several output constraints ensuring system safety must be met, in particular at the evaporator outlet, to protect the turbine from fluid condensation, and at the pump inlet, to protect the pump from fluid vaporization. In the following, we will focus on the control of superheating $S H$ (i.e. the "distance" in kelvin of the fluid from the evaporation temperature, function of the pressure) at the evaporator outlet, w.r.t. variations in engine exhaust gas conditions.

\section{MODELING}

This section describes the modeling of the ORC components needed to predict the fluid state $(p, S H)$ at evaporator outlet during normal operation, that is, when superheated vapor feeds the turbine. A reduced model is developed, for control design.

\section{A. Heat exchangers}

In systems implementing the Rankine thermodynamic cycle, the working fluid enters the evaporator in liquid state and exit in superheated vapor state. A relatively simple model of the evaporator may be obtained via a moving-boundary (MB) approach. As shown in Fig. 4, the MB model monitors the length of each fluid phase along the evaporator: the variables $L_{1}, L_{2}, L_{3}$ track the liquid, two-phase and vapor zones, respectively. Applying mass and energy balances to the fluid and the wall (for each zone), and considering the pressure homogeneous along the evaporator, a first-principle model with seven dynamic states can be written (see [15]), whose state vector is: $x=\left[\begin{array}{lllllll}L_{1} & L_{2} & p & h_{3} & T_{w 1} & T_{w 2} & T_{w 3}\end{array}\right]^{\prime}$.

In an organic Rankine cycle (that is with a "dry" working fluid, [16]), the fluid enters the condenser in vapor state and exit in liquid state or in two-phase

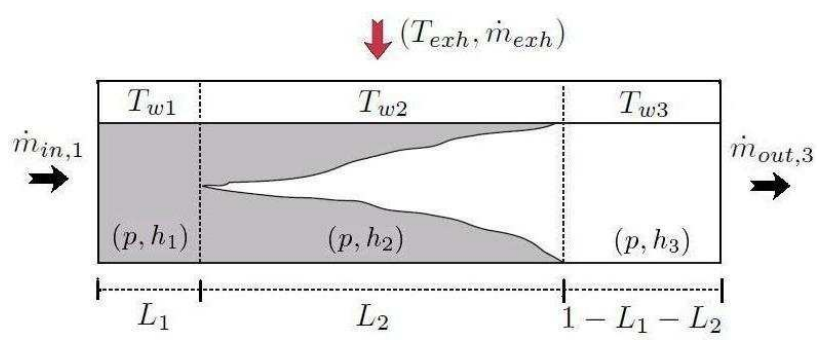

Fig. 4. Moving boundaries layout for the evaporator

state depending on the cooling conditions and on the pressure imposed by the tank (separator). Applying the MB approach to the low-pressure (LP) part of the circuit generally yields a high-order hybrid model (the number of states changes depending on fluid conditions at condenser outlet). However, as explained in Sec. IV$\mathrm{B}$, condenser modelling is not necessary for (our) control purposes.

\section{B. Pump and turbine}

Pump and turbine dynamics being very fast compared to exchangers dynamics, they are modelled by algebraic equations. The (positive displacement) pump produces a mass flow rate proportional to its rotational speed and function of its volumetric efficiency : $\dot{m}_{\text {pump }}=$ $\eta_{\text {pump }} N_{\text {pump }}$. The efficiency $\eta_{\text {pump }}$ can be considered constant in nominal conditions. At the evaporator outlet, the fluid in vapor state expands through the (turbine) nozzle. For nominal mass flow rate values, the fluid then reaches supersonic speeds that allow to neglect the influence of the outlet pressure (see [17]):

$$
\dot{m}_{\text {evap }, \text { out }}=k \sqrt{2 \rho\left(p_{\text {evap }, \text { out }}, S H\right) p_{\text {evap }, \text { out }}},
$$

where $k$ is constant over the considered operating range.

\section{Nonlinear control model}

Designing a controller based on a full model of the Rankine cycle proves a complex and challenging problem. [7] linearizes the model around one operating point. [2] and [4] underline the need of taking into account the nonlinear behaviour of the Rankine system for control design, as its static gains and response times strongly vary with the operating conditions. [11] attempts to cast the evaporator control problem for a similar system (a vapor-compression cycle for refrigeration) in a linear parameter varying (LPV) framework; this approach is made very difficult by the large number of scheduling variables involved.

A reduced model can be used for control design. As explained in Sec. IV-B the effect of fluid conditions at nozzle outlet can be neglected. Furthermore, the thermal inertia of the tank slows down (smoothes out) the variations of pump inlet temperature. Such considerations allow to decouple the high-pressure (HP) part of the cycle from the low pressure (LP) part, which are separated 
by the pump and the nozzle. The LP part includes the condenser and the tank. The HP parts includes the evaporator. The pump flow rate can be seen as a control variable for the HP part while the nozzle is not controlled. Evaporator inlet temperature $T_{i n}$ is then considered as a (measured) disturbance for the HP part.

The model can be further reduced assuming the fluid to be at thermodynamic equilibrium. For a steam Rankine cycle, [2] shows that slow evaporator dynamics are due to wall temperatures and that a third-order model (with state vector $x=\left[\begin{array}{lll}T_{w 1} & T_{w 2} & T_{w 3}\end{array}\right]^{\prime}$ ) is effective for disturbance rejection.

The reduced model of the evaporator is derived from the physical equations given in the following. To simplify notations, all the subscripts of variables relating to the evaporator are dropped.

1) Working fluid mass balance: Assuming working fluid at steady-state leads to consider a homogeneous mass flow $\dot{m}$ along the evaporator equal to the (controlled) pump mass flow.

2) Working fluid energy balance: Energy balance equilibrium for working fluid is written for each zone $i$ :

$$
0=\dot{m}\left(h_{i n, i}-h_{o u t, i}\right)+\dot{Q}_{f, i} L_{i}
$$

where $\dot{Q}_{f, i}=S_{f} \alpha_{i}\left(T_{w, i}-T_{f, i}\right)$ represents the heat transfer from wall, $S_{f}$ being the wall-fluid exchange area. $T_{f, 2}$ (two-phase zone temperature) is the boiling temperature that only depends on pressure. The liquid zone temperature can be computed as the average of evaporator inlet temperature and boiling temperature: $T_{f, 1}=0.5 T_{f, i n}+0.5 T_{f, 2}$. Then $T_{f, 1}$ depends on pressure and on disturbance $T_{f, i n}$. The vapor zone temperature is expressed according to the superheating value $T_{f, 3}=T_{f, 2}+0.5 S H$.

3) Wall energy balance: Wall energy balance yields the following (dynamic) equation for each zone:

$$
m_{w} c_{w} \frac{d T_{w, i}}{d t}=\dot{Q}_{e x h, i}-\dot{Q}_{f, i}
$$

where $\dot{Q}_{e x h, i}=\dot{m}_{e x h} c_{e x h}\left(1-\exp \left(-\frac{\alpha_{e x h} S_{e x h}}{\dot{m}_{e x h} c_{e x h}}\right)\right)\left(T_{e x h}-\right.$ $\left.T_{w, i}\right)$ represents the heat transfer from exhaust gas, $S_{\text {exh }}$ being the wall-exhaust gas exchange area.

4) Differential algebraic equations (DAE) system: the above equations are completed by interface equations. Fluid enthalpies and mass flows at the inlets of zones 2-3 correspond to those at the outlets of zones $1-2 ; h_{i n, i+1}=$ $h_{i n, i}$ for $i=1,2$. For the two-phase zone, inlet and outlet enthalpies correspond to saturation values: $h_{i n, 2}=h_{l}$ and $h_{\text {out }, 2}=h_{v}$ where $h_{l}$ and $h_{v}$ are fluid properties that only depend on pressure. Eventually, balance and interface equations form a DAE system with 3 dynamic states $\left(T_{w, 1}, T_{w, 2}, T_{w, 3}\right)$.
In the system described in [2], there is an additional degree of freedom (the positive-displacement expander) which allows effective tracking of pressure at evaporator outlet; it follows that the output can be computed explicitly (analytically). We propose here to adapt this model to the case of the ORC system under consideration, where the pressure is not controlled by a dedicated actuator, and analyze the robustness of its inversion.

\section{NONLINEAR INVERsion-BASED CONTROL}

The overall supervision and control structure for the Rankine pilot process is similar to that described in [2]. It is a hierarchical structure, coded in Simulink, with modules for sensors and actuators management, for system supervision and control. The supervisor manages the transitions between system modes and activates a specific control strategy for each mode.

In nominal mode, when power is produced, the expander by-pass is closed and only one actuator is fast enough to tightly control evaporator outlet conditions : the pump speed $N_{\text {pump }}$ or (indirectly) the pump mass flow rate $\dot{m}_{\text {pump }}$. It can be used to control superheating $S H$ in closed-loop. Notice that, contrarily to the steam Rankine system studied in [2], the turbine speed $N_{\text {exp }}$ cannot be used to control the pressure at evaporator outlet, as it has no relevant influence on it.

The ORC system we consider has another (slower) actuator, the exhaust by-pass, which can be used to reduce the hot gas enthalpy flow rate so as to limit the pressure in the circuit. This slower control loop, not detailed here, acts as a disturbance to the faster superheating control loop.

\section{A. Superheat control}

The objective is to control the superheating $(\mathrm{SH})$ at evaporator outlet. Effective superheat control is a key issue when controlling an ORC system, as cycle efficiency and component safety depend on it. As pointed by [18], superheating must be kept as low as possible to ensure good ORC efficiency. Furthermore, superheating must always remain positive to prevent the formation of droplets that could damage the turbine.

The control scheme is described in Fig. 5. Input-output dynamics have been identified at different operating points (for fixed disturbances) via a set of linear models.

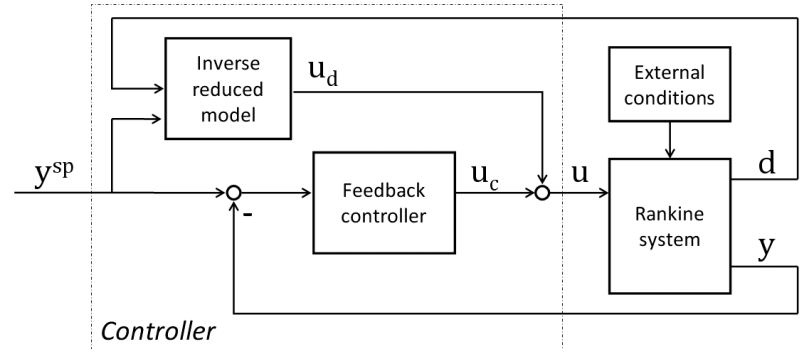

Fig. 5. Controller with inverse of reduced-model in the feedforward path 
The good fitting obtained with underdamped secondorder transfer functions (see Fig. 6) justifies the use of a gain-scheduled PID controller (and not just a PI) in the feedback path. The model derived in Sec. IV$\mathrm{B}$ is inverted to be used in the feedforward path for disturbance rejection.

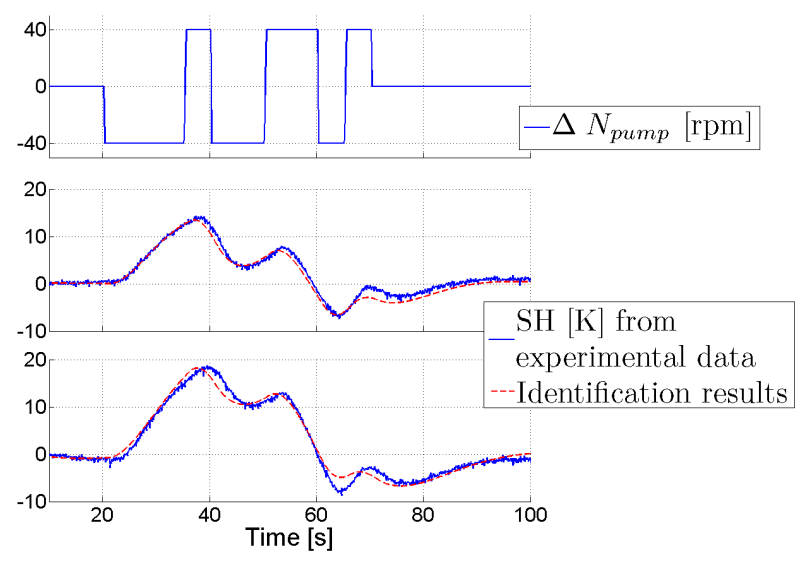

Fig. 6. SH- $N_{\text {pump }}$ pair identification on two different operating points, using underdamped second-order transfer functions.

Evaporator mass flow $\dot{m}$ forms the feedforward part $u_{d}$ of the control input $u=\dot{m}_{\text {pump }}$. Notice that, among the disturbances vector components $(d=$ $\left.\left[\begin{array}{lll}T_{\text {exh }} & m_{\text {exh }} & T_{i n}\end{array}\right]^{\prime}\right), T_{\text {exh }}$ and $T_{i n}$ are measured, while an estimation of $\dot{m}_{e x h}$ is provided by the engine control unit.

The evaporator model is merged with the nozzle mass flow equation (1). Providing that pressure $p$ is known, the dynamic part of the resulting system is described by the following (explicit) system:

$$
\left\{\begin{array}{l}
\dot{T}_{w 1}=-\frac{S_{f} \alpha_{1}}{m_{w} c_{w}}\left(T_{w 1}-T_{f, 1}\right)-\frac{\eta_{e x h}}{m_{w} c_{w}}\left(T_{w 1}-T_{e x h}\right) \\
\dot{T}_{w 2}=-\frac{S_{f} \alpha_{2}}{m_{w} c_{w}}\left(T_{w 2}-T_{f, 2}\right)-\frac{\eta_{e x h}}{m_{w} c_{w}}\left(T_{w 2}-T_{e x h}\right) \\
\dot{T}_{w 3}=-\frac{S_{f} \alpha_{3}}{m_{w} c_{w}}\left(T_{w 3}-T_{f, 3}\right)-\frac{\eta_{e x h}}{m_{w} c_{w}}\left(T_{w 3}-T_{e x h}\right)
\end{array}\right.
$$

where $\eta_{e x h}=\dot{m}_{e x h} c_{e x h}\left(1-\exp \left(-\frac{\alpha_{e x h} S_{e x h}}{\dot{m}_{e x h} c_{e x h}}\right)\right)$, and $p$ can be computed from the (implicit) algebraic part:

$$
\left\{\begin{array}{c}
u_{d}=k \sqrt{2 \rho p} \\
L_{1}=u_{d} \frac{h_{l}-h_{i n}}{S_{f} \alpha_{1}\left(T_{w 1}-T_{1}\right)} \\
L_{2}=u_{d} \frac{h_{v}-h_{l}}{S_{f} \alpha_{2}\left(T_{w 2}-T_{2}\right)} \\
L_{3}=u_{d} \frac{h_{\text {out }}-h_{v}}{S_{f} \alpha_{3}\left(T_{w 3}-T_{3}\right)} \\
0=1-\left(L_{1}+L_{2}+L_{3}\right) .
\end{array}\right.
$$

Let us recall that $T_{f, 2}, h_{l}$ and $h_{v}$ only depend on $p$, while $T_{f, 2}$ depends on $p$ and disturbance $T_{i n}$ and $T_{f, 3}$ depends on $p$ and the desired output $S H^{S P}$ (to improve readability, these dependencies have been omitted in the above equations). Here, the density at evaporator outlet $\rho$ depends on $p$ and $S H^{S P}$. For the sake of simplicity, $S H^{S P}$ will be assumed constant and equal to $30^{\circ} \mathrm{C}$ in the following, but the results remain valid for any other (strictly positive) value of the superheating.

\section{B. Proof}

In order to implement the controller introduced in Sec. V-A, it is necessary to solve the implicit system (5).

Assumption 1: Pressure $p$ in the evaporator is such that $p<25 \mathrm{bar}$ and temperature of working fluid $T_{i n}$ verify $10^{\circ} \mathrm{C}<T_{\text {in }}<40^{\circ} \mathrm{C}$.

\section{Assumption 2: $T_{w i}>T_{f, i}$ for $i=1,2,3$.}

Notice that assumption 1 is verified for the considered system and working fluid in normal conditions (greater pressures or inlet temperatures do not match safety conditions and/or efficiency considerations and would lead to system shutdown by the control system manager). Assumption 2 means that heat is transferred from wall to fluid. Assumption 2 might not be verified during start-up operation. However, in practice, none of these conditions is restrictive.

Let $\Phi=1-\left(L_{1}+L_{2}+L_{3}\right)$ and the state vector $T_{w}=\left[\begin{array}{lll}T_{w 1} & T_{w 2} & T_{w 3}\end{array}\right]^{\prime}$.

Proposition 1: Under Assumption 1 and Assumption 2, $\left.\frac{\partial \Phi}{\partial p}\right|_{\left(T_{w}, d, p\right)}<0$.

To proof this proposition let us show the following sufficient conditions:

1) $\left.\frac{\partial L_{3}}{\partial p}\right|_{\left(T_{w}, d, p\right)}>0$
2) $\left.\frac{\partial L_{2}}{\partial p}\right|_{\left(T_{w}, d, p\right)}>0$
3) $\left.\frac{\partial L_{1}}{\partial p}\right|_{\left(T_{w}, d, p\right)}>0$ where $L_{i}$ are given by (5).

1) Let $L_{3}=\frac{N_{3}}{D_{3}}$ where $N_{3}=u_{d}\left(h_{o u t}-h_{v}\right)$ and $D_{3}=S_{f} \alpha_{3}\left(T_{w 3}-\right.$ $T_{3}$ ), according to $(5)$. Then
$\operatorname{sign}\left(\left.\frac{\partial L_{3}}{\partial p}\right|_{(.)}\right)=\operatorname{sign}\left(\left.\frac{\partial N_{3}}{\partial p}\right|_{(.)} D_{3}-\left.N_{3} \frac{\partial D_{3}}{\partial p}\right|_{(.)}\right)$.

Clearly $N_{3}>0$ and $\left.\frac{\partial D_{3}}{\partial p}\right|_{(.)}<0$ (the evaporation temperature $T_{f, 2}$ increases with $p$ ). Moreover $D_{3}>$ 0 (Assumption 2). Fig. 7(a) shows that $\left.\frac{\partial N_{3}}{\partial p}\right|_{(.)}>0$ for the considered pressure range. So $\left.\frac{\partial L_{3}}{\partial p}\right|_{(.)}>0$.

2) Similar to 1), let $L_{2}=\frac{N_{2}}{D_{2}}$, and notice that $N_{2}>0$, $\left.\frac{\partial D_{2}}{\partial p}\right|_{(.)}<0$ and $D_{2}>0$. Figure $7($ a) shows that $\left.\frac{\partial N_{2}}{\partial p}\right|_{(.)}>0$. So $\left.\frac{\partial L_{2}}{\partial p}\right|_{(.)}>0$.

3) Similar to 1), let $L_{1}=\frac{N_{1}}{D_{1}}$, and notice that $N_{1}>0$, $\left.\frac{\partial D_{1}}{\partial p}\right|_{(.)}<0$ and $D_{1}>0$. Figure $7(\mathrm{~b})$ shows that 
$\left.\frac{\partial N_{1}}{\partial p}\right|_{(.)}>0$ for considered pressure and disturbance range. So $\left.\frac{\partial L_{2}}{\partial p}\right|_{(.)}>0$.

Thus, $\Phi\left(T_{w}, d, p\right)$ decreases monotonically with $p$. Consequently, one can numerically solve (5), e.g. by a bisection method, ensuring a robust (inline) implementation of the controller. In other words, given a disturbance vector $d$ and a state vector $T_{w}$, computed by integration of the (stable) equation system (4), one can compute the corresponding $p$. Eventually, the feedforward part $u_{d}$ is deduced from the nozzle mass flow equation $u_{d}=$ $k \sqrt{2 \rho p}$.
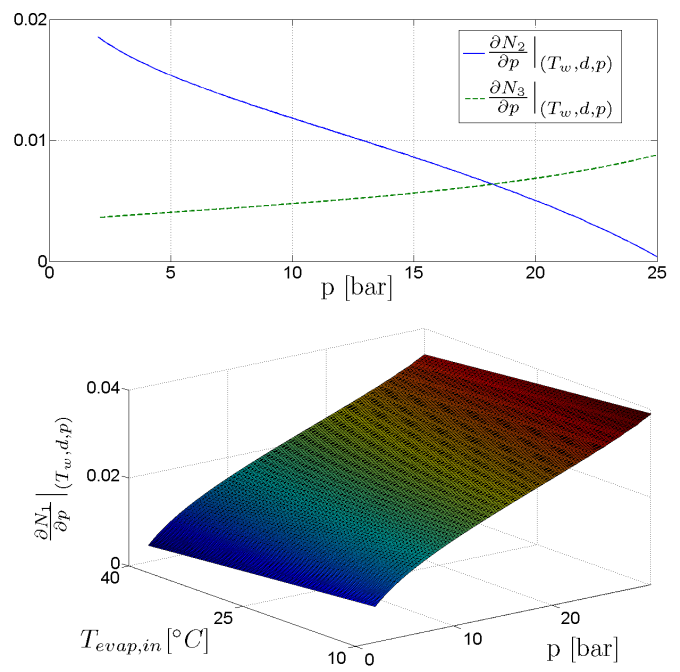

Fig. 7. $\quad N_{1}, N_{2}$ and $N_{3}$ increase with $p$ (assuming $p<25$ bars and $\left.T_{\text {evap,in }}<40^{\circ} \mathrm{C}\right)$. Here $S H^{S P}$ equal $30^{\circ} \mathrm{C}$.

\section{EXPERIMENTAL RESUlts}

In this section we will show that, although $S H$ control is possible via a (gain-scheduled) PID alone, the use of an inverse model allows significant gains in performance.

In Fig. 8 the two control strategies (with or without feedforward) are compared, for the same variations of exhaust gas conditions. The feedforward action significantly improves performance : maximum error ( $\mid S H-$ $S H^{S P} \mid$ ) is only $1.9 \mathrm{~K}$ in this case (compared with $6.5 \mathrm{~K}$ without feedforward). Notice that this would allow to reduce considerably the superheating setpoint, thus increasing cycle efficiency, while keeping the same safety margins during power production.

\section{CONCLUSion}

Effective superheat control is a key issue when controlling an ORC system for engine waste heat recovery. The control law we have designed for our application, combining a dynamic feedforward term computed from a nonlinear reduced model of the high-pressure part of the system to a gain-scheduled PID, performs well and helps make the ORC system more efficient and viable.
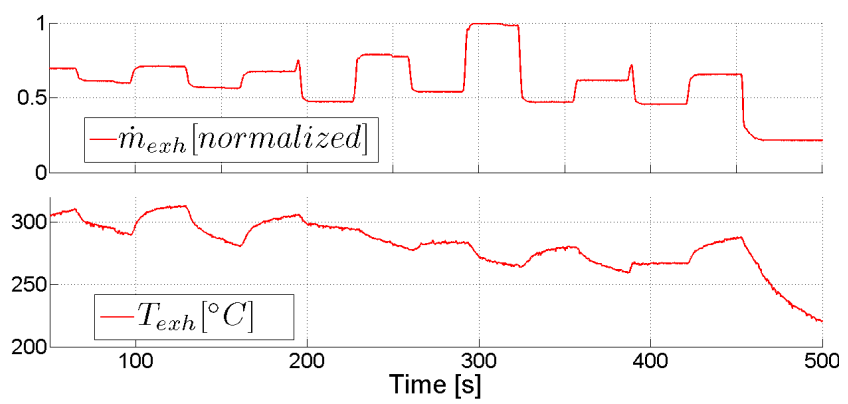

(a) Disturbances (exhaust gas conditions)
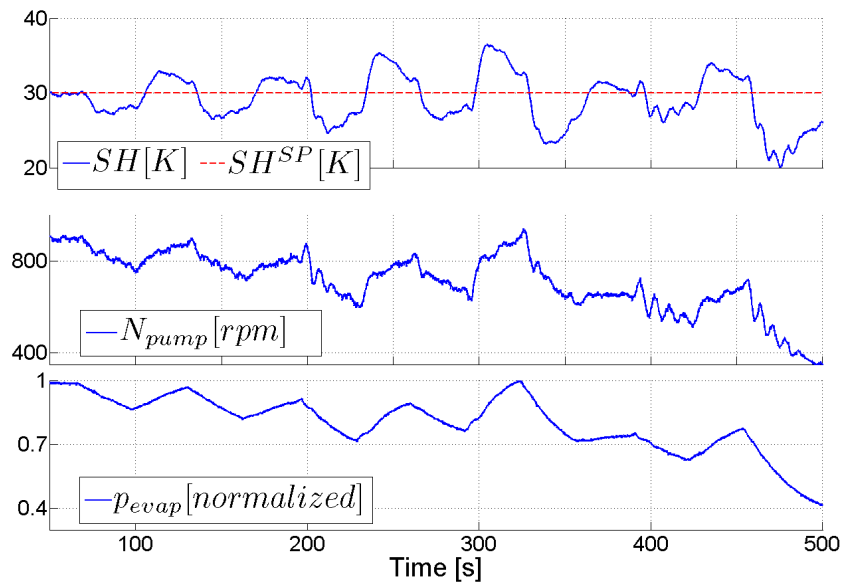

(b) PID alone
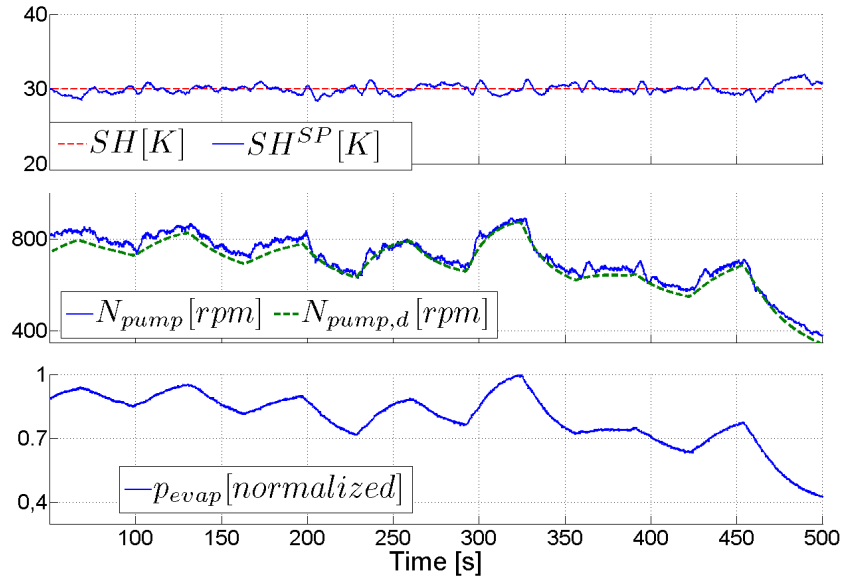

(c) PID with (dynamic) inverse model in feedforward path

Fig. 8. Experimental result: dynamic inverse model improve superheating $(S H)$ control

Performance could be further improved, if really needed, working on the feedback part. The gainscheduled PID controller could be replaced, for instance, by a robust (PID) controller designed in the LPV framework.

\section{REFERENCES}

[1] C. Sprouse III and C. Depcik. Review of organic rankine cycles for internal combustion engine exhaust waste heat recovery. Applied Thermal Engineering, 51(1-2):711 - 722, 2013. 
[2] J. Peralez, P. Tona, A. Sciarretta, P. Dufour, and M. Nadri. Towards model-based control of a steam rankine process for engine waste heat recovery. In Vehicle Power and Propulsion Conference (VPPC), pages 289-294. IEEE, 2012.

[3] T. Endo, S. Kawajiri, Y. Kojima, K. Takahashi, T. Baba, S. Ibaraki, T. Takahashi, and M. Shinohara. Study on maximizing exergy in automotive engines. In $S A E$ World Congress. SAE International, 2007.

[4] T. A. Horst, H. S. Rottengruber, M. Seifert, and J. Ringler. Dynamic heat exchanger model for performance prediction and control system design of automotive waste heat recovery systems. Applied Energy, 105(0):293 - 303, 2013.

[5] T. Park, H. Teng, G.L. Hunter, B. van der Velde, and J. Klaver. A rankine cycle system for recovering waste heat from hd diesel engines - experimental results. In $S A E$ World Congres. SAE International, 2011.

[6] G. Hou, R. Sun, G. Hu, and J. Zhang. Supervisory predictive control of evaporator in organic rankine cycle (ORC) system for waste heat recovery. In Advanced Mechatronic Systems (ICAMechS), pages 306-311, 2011.

[7] J. Zhang, W. Zhang, G. Hou, and F. Fang. Dynamic modeling and multivariable control of organic rankine cycles in waste heat utilizing processes. Computers 8 Mathematics with Applications, 64(5):908-921, 2012.

[8] J. Zhang, Y. Zhou, S. Gao, and G. Hou. Constrained predictive control based on state space model of organic rankine cycle system for waste heat recovery. In Chinese Control and Decision Conference (CCDC), pages 230 -234, 2012.

[9] S. Quoilin, R. Aumann, A. Grill, A. Schuster, V. Lemort, and H. Spliethoff. Dynamic modeling and optimal control strategy of waste heat recovery Organic Rankine Cycles. Applied Energy, 88(6):2183-2190, 2011.

[10] X.D. He, S. Liu, and H.H. Asada. Modeling of vapor compression cycles for multivariable feedback control of HVAC systems. ASME Journal of dynamic systems, measurement, and control, 119:183, 1997.

[11] B. Rasmussen. Dynamic modeling and advanced control of air conditioning and refrigeration systems. $\mathrm{PhD}$ thesis, University of Illinois at Urbana-Champaign, 2005.

[12] A. Alleyne, B. Rasmussen, M. Keir, and B. Eldredge. Advances in energy systems modeling and control. In American Control Conference (ACC), pages 3658-3668. IEEE, 2007.

[13] M. Graber, N. C. Strupp, and W. Tegethoff. Moving boundary heat exchanger model and validation procedure. In EUROSIM Congress on Modelling and Simulation, 2010.

[14] D. Wei, X. Lu, Z. Lu, and J. Gu. Dynamic modeling and simulation of an organic rankine cycle (ORC) system for waste heat recovery. Applied Thermal Engineering, 28(10):1216 $1224,2008$.

[15] J.M. Jensen. Dynamic modeling of thermo-fluid systems with focus on evaporators for refrigeration. PhD thesis, Technical University of Denmark, 2003.

[16] S. H. Kang. Design and experimental study of ORC (organic rankine cycle) and radial turbine using R245fa working fluid. Energy, 41(1):514 - 524, 2012.

[17] Emanuel Feru, Frank Kupper, Chepa Rojer, Xander Seykens, Fabio Scappin, Frank Willems, Jeroen Smits, Bram De Jager, and Maarten Steinbuch. Experimental validation of a dynamic waste heat recovery system model for control purposes. In SAE World Congress. SAE International, 2013.

[18] T. Yamamoto, T. Furuhata, N. Arai, and K. Mori. Design and testing of the organic rankine cycle. Energy, 26(3):239 - 251, 2001. 